\title{
Coronavirus y Animales
}

\author{
Sergio García Torres \\ Director General de Derechos de los Animales \\ Ministerio de Derechos Sociales y Agenda 2030, España
}

Cita recomendada. GARCÍA TORRES, S., Coronavirus y Animales, dA. Derecho Animal (Forum of Animal Law Studies) 11/4 (2020). - DOI https://doi.org/10.5565/rev/da.547

\section{Resumen}

El Webinar Coronavirus y Animales, organizado por el ICALP (International Center for Animal Law and Policy) se llevó a cabo del 22 de junio al 15 de julio de 2020. En la sesión de clausura, el autor de este editorial presentó el trabajo realizado por la Dirección General de Derechos de los Animales (España) para asegurar el bienestar de los animales durante la pandemia.

Palabras clave: Covid-19; Gobierno; España; animales; protección de la vulnerabilidad; seres sentientes; Código penal; Código civil.

\section{Abstract - Coronavirus and Animals}

The Coronavirus and Animals Webinar, organized by the ICALP (International Center for Animal Law and Policy) was held from June 22nd to July 15th 2020. During the closing session, the author of this editorial presented the work done by the General Directorate for Animal Rights (Spain) to ensure the wellbeing of animals during the pandemic outbreak.

Key words: Covid-19; Government; Spain; animals; safeguarding; sentient beings; Criminal Code; Civil Code.

Gracias por la invitación a participar en este Webinar. Sin lugar a duda las intervenciones en este seminario, que he seguido durante estas semanas, son dignas de recopilar para posteriormente hacer un trabajo de puesta en común y difusión.

Durante estos meses, desde la Dirección General de Derechos de los Animales hemos tenido un trabajo muy intenso, su creación data de febrero de este año y apenas un mes después, se decretó el Estado de alarma a consecuencia de la Covid-19. En dicho momento, desde la Dirección General -y en el marco de la Vicepresidencia Social de Derechos Sociales- se establecieron mecanismos para que esta brutal pandemia no dejara a nadie atrás. Desde nuestra Dirección General, enfocamos nuestro trabajo a la puesta en marcha de políticas y mecanismos para que los animales y las personas que conviven con ellos no quedaran atrás.

El Estado de alarma se estableció el 15 de marzo y el día 19, desde la Dirección General en coordinación con el Ministerio de Sanidad, autoridad única competente durante el estado de alarma, se publicó en el Boletín Oficial del Estado la norma que establecía la obligatoriedad de mantenimiento, cuidado y alimentación de los animales de compañía, en concreto de las Colonias Felinas, ya que esto suponía una cuestión de salud pública. Esta iniciativa supuso un hito en lo referente a la protección de estos animales, nunca antes reflejados ni 
tenidos en cuenta desde ámbitos Estatales de la Administración General del Estado.

En el marco de los protocolos de derechos sociales para personas con mayor vulnerabilidad -en concreto, personas sin hogar-, se establecieron mecanismos para la atención de dichas personas y la atención también de sus animales, dotando de una red de entidades de protección y de centros municipales para que dichos animales pudieran estar protegidos; dichos protocolos, junto a los mecanismos de cuidado de colonias felinas fueron trasladados a través de la Federación Española de municipios y Provincias a todas las entidades locales.

Se crearon así mecanismos de respuesta rápida en servicios sociales para asistir y ayudar a personas en situaciones de vulnerabilidad.

Durante el periodo de alarma, se trabajó en asesorar y dotar de mecanismos a las administraciones locales de cara al establecimiento de una gestión eficiente y segura de las Colonia Felinas, es cierto que muchos Ayuntamientos, antes de esta situación de excepcionalidad, ya gestionaban de manera coordinada con entidades de protección y colectivos de alimentadoras, a las referidas Colonias Felinas, pero también es cierto que muchos cientos de Ayuntamientos nunca habían visto necesario una gestión coordinada de estas Colonias Felinas, y ahora, con una obligatoriedad por parte de la Administración Central, se veían ante la necesidad de ponerlo en marcha. En consecuencia, desde la Dirección General, se proveyó de todos los mecanismos, protocolos y posibilidades, para que dicha gestión se hiciera de manera eficiente y respetuosa con la norma de excepcionalidad establecida por el decreto de alarma y con la ética para con los animales de estas colonias.

Desde la Dirección General de Derechos de los animales, durante el mes de abril, pusimos en marcha otro proyecto de manera urgente, el proyecto Viopet.

El proyecto Viopet establece un mecanismo de protección para animales de mujeres víctimas de violencia de género. De hecho, las cifras de mujeres que llamaban a los teléfonos de atención para mujeres se multiplicaba, por lo que, desde la Dirección General, entendimos que debíamos poner en marcha el proyecto de manera urgente, ya que un buen porcentaje de las mujeres que solicitan ayuda en los centros -que proveen de recursos contra el maltrato a las mujeres-, tienen animales de compañía y dichos centros de recursos no aceptan animales, por muchos motivos, entre ellos la propia seguridad de las víctimas.

Para cubrir lo que entendimos como una necesidad, se creó una red de casas de acogida, gestionada directamente por la Dirección General, que ha llegado en poco tiempo a alcanzar las 800 casas por todo el territorio español. El equipo de expertas que gestionan el recurso, una vez que surge un caso, establece mecanismos para que, durante la estancia de las mujeres en los centros de recursos de protección de la mujer, los animales de las mismas estén cuidados en casas de acogida y una que vez la mujer vuelva a una situación de normalidad, el animal pueda volver con ella. Este proyecto, ha hecho que muchas mujeres dieran el paso de abandonar el domicilio en el que convivían con su agresor, al saber que su animal no quedaba a la suerte de posibles y frecuentes maltratos o a la utilización como chantaje a la víctima.

A la par de las medidas y mecanismos relacionados con la emergencia sanitaria surgida por la Covid 19, desde la Dirección General hemos puesto en marcha una serie de reuniones con colectivos sociales y profesionales, relacionados con la protección animal de cara a conocer detalles y propuestas de cara a la futura elaboración de lo que será la Ley Estatal de Protección Animal. En el marco de las reuniones, se estima llevar a cabo más de 100 encuentros con colectivos y profesionales.

Uno de los principales ejes de lo que será la mencionada Ley, es la necesidad de establecer un mecanismo de identificación nacional de animales de compañía, con una ampliación en cuanto al conocimiento y trazabilidad de dichos animales, similar a lo que ya ocurre con los animales llamados de producción.

El control de cría, actualmente la cría de animales de compañía suponen uno de los mayores problemas, con respecto a la sobrepoblación de animales de compañía y la persecución del abandono.

Actualmente también estamos trabajando en la modificación, con carácter de urgencia, del Código Penal en materia de maltrato hacia los animales. El cambio de concepto de animales de compañía por animal vertebrado, abre la protección y ámbito del Código Penal a otros animales hasta ahora no protegidos ante el maltrato por ninguna legislación, así como también a un agravamiento de las penas, que garantice que no puedan quedar impunes la comisión de actos graves de maltrato, que de todos son conocidos.

En la misma línea, la modificación del Código Civil es una prioridad de las políticas de esta Dirección General por lo que, en el marco de la actividad parlamentaria, será propuesta su reforma con urgencia, para dotar a los animales de un carácter diferenciado de los objetos, con el fin de que pasen a ser considerados como seres dotados de sensibilidad. 